\title{
Increased Arterial Stiffness after Coronary Artery Revascularization Correlates with Serious Coronary Artery Lesions and Poor Clinical Outcomes in Patients with Chronic Kidney Disease
}

\author{
Zhengbin Zhu ${ }^{a}$ Zijun Yan ${ }^{a}$ Lin Zhang ${ }^{c}$ Run Du ${ }^{a}$ Jinzhou Zhu ${ }^{a}$ \\ Junli Zuo ${ }^{b}$ Shaoli Chub Weifeng Shen ${ }^{a}$ Ruiyan Zhang ${ }^{a}$ \\ Departments of a Cardiology and ${ }^{b}$ Hypertension, Rui Jin Hospital, Shanghai Jiao Tong \\ University School of Medicine, and ${ }^{C}$ Civil Aviation Administration of China (CAAC), East \\ China Regional Administration Aviation Personnel Examination Center, Shanghai Hospital of \\ Civil Aviation, Shanghai, China
}

\section{Key Words}

Arterial stiffness $\cdot$ Coronary artery disease $\cdot$ Prognosis $\cdot$ Chronic kidney disease

\begin{abstract}
Objectives: This study aimed to clarify the relationship between arterial stiffness and coronary artery lesions as well as their influence on long-term outcomes after coronary artery revascularization in patients with chronic kidney disease (CKD). Methods: A total of 205 patients who had a coronary angiography and received coronary artery revascularization on demand were enrolled and followed up for 5 years. Demographic and clinical indicators, arterial stiffness indexes, angiographic characteristics and the Gensini score (GS) were recorded at baseline. Major adverse cardiac events (MACE), including cardiac death and repeat coronary artery revascularization, that occurred during the 5 years of follow-up were also recorded. Results: All indexes reflecting the degree of arterial stiffness, including PWV, C1, C2, CSBP, CDBP, AP and Aix, were significantly higher in CKD than in non-CKD patients (all $p<0.05$ ). Patients with CKD also had a higher rate of coronary artery disease and a higher GS ( $p<0.05$ and $p<0.01$, respectively). Logistic regression analysis revealed CKD to be an independent risk factor for increased arterial stiffness (OR $=2.508,95 \%$ CI 1.308-4.808, $p=0.006$ ). During follow-up, CKD patients with PWV $>13$ m/s or Aix@ $75>30$ had a significantly higher MACE occurrence rate after coronary artery revascularization (both $p<0.05$ ). Conclusion: These
\end{abstract}


results highlight that CKD and arterial stiffness correlate with the severity of coronary artery lesions. CKD patients with impaired arterial stiffness have poor clinical outcomes, suggesting a further clinical use of the arterial stiffness index as a surrogate of worse cardiovascular prognosis in CKD than in non-CKD patients.

(C) 2014 S. Karger AG, Basel

\section{Introduction}

It is well known that patients with chronic kidney disease (CKD) encounter a worse prognosis after coronary revascularization than patients without CKD [1,2]. The main factors for the heightened risk in this population - besides the advanced age as well as a high incidence of diabetes and hypertension - are malnutrition, chronic inflammation, accelerated atherosclerosis, endothelial dysfunction, coronary artery calcification, left ventricular structural and functional abnormalities and bone mineral disorders [3]. Recently, CKD has been acknowledged as a coronary artery disease (CAD) risk equivalent [4]. However, increased serum creatinine itself is just a marker of decreased renal function. Several markers of vascular impairment have been found in CKD patients, including increased arterial stiffness.

Previous studies have shown that increased arterial stiffness is a marker of vasculopathy in CKD patients [5], suggesting a significant cardiovascular damage [6]. Recently, Roos et al. [7] have reported on associations of atherosclerosis in the descending thoracic aorta on CT angiography with arterial stiffness and CKD in asymptomatic patients with diabetes mellitus. These findings suggest that arterial stiffness could be the missing link between CKD and CAD and that it could probably be associated with long-term prognosis.

The current study aimed to analyze the correlation between arterial stiffness and coronary artery lesions and their influence on clinical outcomes in patients with CKD.

\section{Methods}

Study Design and Patient Selection

This is an observational comparative study with a 5-year follow-up. From August 2008 to April 2009, a total of 205 consecutive patients who had a coronary angiography at the Rui Jin Hospital affiliated to the Shanghai Jiao Tong University School of Medicine were enrolled. All enrolled patients had at least one traditional risk factor for CAD, including hypertension, diabetes mellitus, dyslipidemia or being a current smoker. Those diagnoses were double checked according to prevailing guidelines, and smoking was defined as consuming $\geq 1$ cigarette per day. We used the following exclusion criteria: age $>80$ years, heart failure (left ventricular ejection fraction $<45 \%$ ), organic valvular heart disease, severe arrhythmia, malignant tumor and dyscrasia.

The study was approved by the Institutional Ethics Committee at Rui Jin Hospital, and written informed consent was obtained from the patients prior to enrollment.

Data Collection and Definition of CKD

All patient-related data and laboratory exam results were recorded once the patients were enrolled and kept blinded until the study was completed. Consistent with the current guideline-based CKD definitions [8], patients with an estimated glomerular filtration rate (eGFR) $<60 \mathrm{ml} / \mathrm{min} \times 1.73 \mathrm{~m}^{2}$ were defined as CKD patients. eGFR was calculated according to the MDRD formula: eGFR $=186.3 \times \mathrm{SCr}-1.154 \times$ age $-0.203 \times$ 0.742 (if female).

\section{Primary Endpoint and Patient Follow-Up}

The primary endpoint of our study was defined as major adverse cardiac events (MACE), including cardiac death and repeat coronary artery revascularization. Patents who encountered sudden deaths were recorded as cardiac deaths. Clinical follow-up was performed at 3, 6, 9 and 12 months and then annually up to 5 years after the index procedure. All patients received out-clinic or telephone follow-up. 
Zhu et al.: Arterial Stiffness Correlates with CAD Outcomes in CKD Patients

\section{Procedures and Adjunct Drug Therapy}

Angiography was conducted using the standard Judkins selective coronary angiography method (INNOVA 2100-IQ; GE Healthcare, Connecticut, USA). CAD was defined as $\geq 1$ lesion stenosis over $50 \%$. Lesions were treated by standard interventional techniques. Prior to stent implantation, all patients received standard drug treatment as we have presented previously [1]. The use of angiotensin-converting enzyme inhibitor (ACEI), angiotensin receptor blocker, $\beta$-blocker, statins, calcium channel blockers and nitrates was determined by doctors.

\section{Coronary Gensini Score}

The severity of coronary atherosclerosis was determined by the Gensini score (GS), which is computed by assigning a severity score to each coronary stenosis according to the degree of luminal narrowing and its importance based on location [9].

\section{Noninvasive Arterial Stiffness Detection}

Blood pressure was measured with patients in the dorsal position, restful and fasting. Brachial artery blood pressure was measured twice using the Omron electronic sphygmomanometer (HEM 7200; Omron Healthcare, Singapore, Singapore) and the mean value was recorded. Pulse wave velocity (PWV) was recorded using a specific instrument (Complior; Alam Medical, Vincennes, France), which contains baroreceptor to detect the most obvious artery beat in the right carotid artery and femoral artery. Surface distance between these two points was also recorded, so that PWV = surface distance/conduction time (m/s). Large artery compliance (C1) and small artery compliance (C2) were detected using the arterial function tester D0-2020 (CVProfilor; Hypertension Diagnostics, Eagan, Minn., USA) to sense the right radial artery beat, and each stable waveform was recorded for 30 s. A SphygmoCor-Px measuring central arterial pressure (AtCor Medical, West Ryde, N.S.W., Australia) was used for pulse wave analysis (PWA). The sensor was put above the most obvious artery beat in the right radial artery to get a stable waveform for at least $11 \mathrm{~s}$, and all data with an operation index $>80$ were recorded. Thus, central aortic systolic blood pressure, central aortic diastolic blood pressure and central aortic pulse pressure could be recorded. Augmentation pressure (AP) refers to the pressure difference between the first (T1) and the second (T2) pulse wave peak: AP = P(T2) $\mathrm{P}(\mathrm{T} 1)$. The augmentation index (Aix) refers to the ratio of the reflected and primary wave: Aix $=[\mathrm{P}(\mathrm{T} 2)-$ $\mathrm{P}(\mathrm{T} 1)] /[\mathrm{P}(\mathrm{T} 1)-\mathrm{P}(\mathrm{Tf})] \times 100$, where Tf is the time of the reflected wave peak. Subendocardial viability ratio refers to the area ratio of the diastolic and the systolic pulse wave. Ejection duration (ED) was also analyzed.

According to the 2007 ESH-ESC guidelines [10], a PWV >12 m/s was suggested as a threshold to conservatively estimate significant alterations of aortic function, but no definite Aix threshold was suggested. Thus, we defined those with a PWV >12 m/s or Aix@ 75 (adjusted for an average heart rate of 75 beats/min) in the highest tertile (Aix@ $75>24$ ) as patients with increased arterial stiffness. All assessments were done by a single doctor blinded to other data.

\section{Statistical Analysis}

Continuous variables are expressed as means \pm standard deviation (SD), and categorical variables are described by numbers and percentages. Student's $t$ test, $\chi^{2}$ test and Fisher's exact test were used to assess the homogeneity of demographic variables and baseline characteristics. Spearman's and Pearson's correlation tests were used. After a univariate analysis ahd been performed to test all variables, those associated with increased arterial stiffness at $\mathrm{p}<0.2$ were entered in a multivariate logistic regression analysis with a stepping algorithm. The results of the multivariate analysis are presented as adjusted odds ratios. KaplanMeier curves were used for survival analysis. All significance tests were two tailed, and a p value $<0.05$ was considered statistically significant. All analyses were performed with the SPSS software (version 20.0).

\section{Results}

Baseline Characteristics

A total of 205 patients (154 males and 51 females) aged 33-79 years (average 60.1 \pm 9.1 ) were enrolled. As shown in table 1, CKD patients were significantly older and they suffered more frequently also from hypertension and diabetes mellitus. Moreover, their SBP, DBP and 
Table 1. Baseline characteristics

\begin{tabular}{lccr}
\hline & $\begin{array}{l}\text { CKD patients } \\
(\mathrm{n}=68)\end{array}$ & $\begin{array}{l}\text { Non-CKD patients } \\
(\mathrm{n}=137)\end{array}$ & p value \\
\hline Female gender & 24.10 & 24.90 & 0.710 \\
Age, years & $63 \pm 8$ & $59 \pm 9$ & 0.002 \\
BMI & $25.34 \pm 3.12$ & $24.94 \pm 3.16$ & 0.399 \\
Hypertension & 86.50 & 68.00 & $<0.001$ \\
$\quad$ Systolic blood pressure, mm Hg & $133 \pm 21$ & $118 \pm 22$ & $<0.001$ \\
$\quad$ Diastolic blood pressure, mm Hg & $81 \pm 11$ & $76 \pm 12$ & 0.003 \\
Pulse pressure, mm Hg & $50 \pm 17$ & $42 \pm 14$ & 0.001 \\
Diabetes & 35.90 & 18.00 & $<0.001$ \\
Fasting blood glucose, mmol/l & $5.54 \pm 1.63$ & $5.35 \pm 1.04$ & 0.313 \\
Currently smoking & 22.10 & 31.40 & 0.163 \\
Dyslipidemia & 64.70 & 30.70 & $<0.001$ \\
Triglyceride, mmol/l & $1.89 \pm 1.08$ & $1.79 \pm 1.37$ & 0.592 \\
Total cholesterol, mmol/l & $4.36 \pm 0.98$ & $4.41 \pm 1.41$ & 0.838 \\
High-density lipoprotein cholesterol, mmol/l & $1.13 \pm 0.26$ & $1.16 \pm 0.29$ & 0.367 \\
Low-density lipoprotein cholesterol, mmol/l & $2.62 \pm 0.77$ & $2.68 \pm 1.05$ & 0.667 \\
Drug therapy & & & 0.188 \\
Aspirin & 94.10 & 88.30 & 0.008 \\
ACEI & 70.60 & 51.10 & 0.542 \\
Angiotensin receptor blocker & 27.90 & 32.10 & 0.861 \\
Calcium channel blockers & 32.40 & 33.60 & 0.075 \\
B-Blocker & 63.20 & 75.20 & 0.030 \\
Statins & 94.10 & 83.20 & 0.957 \\
Nitrates & 45.60 & 46.00 & \\
\hline Values are presented as means \pm SD or percentages. & & \\
\hline
\end{tabular}

pulse pressure detected at baseline were also higher. Although a history of dyslipidemia is more often present in CKD patients, their blood lipid levels were comparable with those of non-CKD patients. This was probably due to the higher rate of statin use. In addition to statins, ACEI were more frequently used in CKD patients, as is suggested in the guidelines. There was no difference in sex, BMI, smoking state and fasting blood glucose between the two groups.

\section{Arterial Stiffness and Coronary Lesions in CKD Patients}

Our data revealed more severe arterial stiffness and higher CAD prevalence in CKD than in non-CKD patients (table 2). All indexes that reflect the degree of arterial stiffness were significantly higher in CKD patients. The difference in Aix@ 75 of the two groups was still significant $(p=0.013)$. A longer ED, which means a shorter diastolic period, was found in CKD patient, and that may be due to the higher rate of hypertension and more severe arterial stiffness. Based on coronary angiography, patients with CKD suffered from more serious coronary lesions.

Since the age difference, which has a great influence on arterial stiffness, was significant between CKD and non-CKD patients, we further analyzed arterial stiffness and coronary artery lesion characteristics in the different age groups (table 3). In both age groups, CKD patients had significantly higher C1, C2, Aix@ 75 and $\log _{2}$ GS.

\section{Correlation between CKD, Arterial Stiffness and CAD}

According to the tertiles of each PWV and Aix@75, we separated the whole population and CKD population into three groups (table 4). Our results showed that compared to those 
Table 2. Arterial stiffness and coronary lesions in CKD and non-CKD patients

\begin{tabular}{|c|c|c|c|}
\hline & $\begin{array}{l}\text { CKD patients } \\
(n=68)\end{array}$ & $\begin{array}{l}\text { Non-CKD patients } \\
(\mathrm{n}=137)\end{array}$ & $\mathrm{p}$ value \\
\hline \multicolumn{4}{|l|}{ Arterial stiffness characteristics } \\
\hline $\mathrm{PWV}, \mathrm{m} / \mathrm{s}$ & $13.45 \pm 7.25$ & $11.22 \pm 2.87$ & $<0.001$ \\
\hline $\mathrm{C} 1, \mathrm{ml} / \mathrm{mm} \mathrm{Hg} \times 10$ & $22.61 \pm 8.20$ & $16.14 \pm 8.88$ & $<0.001$ \\
\hline $\mathrm{C} 2, \mathrm{ml} / \mathrm{mm} \mathrm{Hg} \times 100$ & $7.64 \pm 5.01$ & $5.20 \pm 2.53$ & $<0.001$ \\
\hline Central aortic systolic blood pressure, mm Hg & $138.31 \pm 23.92$ & $131.03 \pm 24.40$ & $<0.001$ \\
\hline Central aortic diastolic blood pressure, $\mathrm{mm} \mathrm{Hg}$ & $78.94 \pm 12.52$ & $74.82 \pm 11.77$ & 0.005 \\
\hline Central aortic pulse pressure, $\mathrm{mm} \mathrm{Hg}$ & $59.37 \pm 16.27$ & $57.21 \pm 16.39$ & 0.001 \\
\hline $\mathrm{AP}, \mathrm{mm} \mathrm{Hg}$ & $12.94 \pm 8.24$ & $10.07 \pm 7.56$ & 0.014 \\
\hline Aix, \% & $23.83 \pm 13.81$ & $18.09 \pm 10.97$ & 0.001 \\
\hline Aix@75, \% & $24.03 \pm 12.65$ & $16.82 \pm 11.43$ & $<0.001$ \\
\hline Mean blood pressure, mm Hg & $103.04 \pm 19.01$ & $94.14 \pm 16.20$ & 0.001 \\
\hline Ejection duration, jiffy & $38.22 \pm 7.10$ & $35.20 \pm 4.76$ & $<0.001$ \\
\hline Subendocardial viability ratio & $125.59 \pm 33.94$ & $153.81 \pm 33.93$ & $<0.001$ \\
\hline Heart rate, beats/min & $74 \pm 13$ & $75 \pm 13$ & 0.707 \\
\hline \multicolumn{4}{|l|}{ Coronary lesion characteristics } \\
\hline CAD & 54 (79.4) & $86(62.8)$ & 0.016 \\
\hline Coronary lesions per patient & $2.62 \pm 1.68$ & $1.73 \pm 1.63$ & $<0.001$ \\
\hline LM & $8(11.8)$ & $8(5.8)$ & 0.136 \\
\hline LAD & $52(76.5)$ & $67(48.9)$ & $<0.001$ \\
\hline LCX & $39(57.4)$ & $55(40.1)$ & 0.020 \\
\hline RCA & $46(67.6)$ & $72(52.6)$ & 0.040 \\
\hline PCI & $48(70.6)$ & $68(49.6)$ & 0.004 \\
\hline CABG & $4(5.9)$ & $4(2.9)$ & $0.444^{*}$ \\
\hline GS & $40.36 \pm 32.31$ & $26.14 \pm 30.79$ & 0.002 \\
\hline $\log _{2} \mathrm{GS}$ & $4.53 \pm 1.85$ & $3.23 \pm 2.45$ & $<0.001$ \\
\hline
\end{tabular}

Values are presented as means \pm SD or $\mathrm{n}(\%)$. LM = Left main; LAD = left anterior descending artery; LCX = left circumflex artery; RCA =right coronary artery; CABG = coronary artery bypass grafting. Calculations of arterial stiffness index: PWV = surface distance/conduction time (m/s); Aix = $[\mathrm{P}(\mathrm{T} 2)-\mathrm{P}(\mathrm{T} 1)] /[\mathrm{P}(\mathrm{T} 1)-$ $\mathrm{P}(\mathrm{Tf})] \times 100 .{ }^{*}$ Fisher's exact test.

Table 3. Arterial stiffness and coronary lesions in different age groups

\begin{tabular}{|c|c|c|c|c|c|c|}
\hline & \multicolumn{3}{|l|}{ Age $\leq 60$} & \multicolumn{3}{|l|}{ Age $>60$} \\
\hline & $\begin{array}{l}\text { CKD patients } \\
(\mathrm{n}=19)\end{array}$ & $\begin{array}{l}\text { non-CKD patients } \\
(\mathrm{n}=75)\end{array}$ & $\mathrm{p}$ & $\begin{array}{l}\text { CKD patients } \\
(\mathrm{n}=49)\end{array}$ & $\begin{array}{l}\text { non-CKD patients } \\
(\mathrm{n}=62)\end{array}$ & $\mathrm{p}$ \\
\hline & $53 \pm 4$ & $52 \pm 5$ & 0.509 & $67 \pm 6$ & $67 \pm 6$ & 0.851 \\
\hline $\mathrm{PWV}, \mathrm{m} / \mathrm{s}$ & $9.92 \pm 1.64$ & $10.32 \pm 2.18$ & 0.456 & $15.27 \pm 8.01$ & $12.32 \pm 3.23$ & 0.009 \\
\hline $\mathrm{C} 1, \mathrm{ml} / \mathrm{mm} \mathrm{Hg} \times 10$ & $21.15 \pm 6.92$ & $15.28 \pm 6.75$ & 0.001 & $23.17 \pm 8.64$ & $17.20 \pm 10.88$ & 0.002 \\
\hline $\mathrm{C} 2, \mathrm{ml} / \mathrm{mm} \mathrm{Hg} \times 100$ & $7.41 \pm 3.70$ & $5.62 \pm 2.62$ & 0.017 & $7.73 \pm 5.47$ & $4.70 \pm 2.34$ & $<0.001$ \\
\hline CSBP, mm Hg & $129.16 \pm 16.74$ & $124.43 \pm 19.79$ & 0.341 & $141.86 \pm 25.44$ & $139.02 \pm 27.09$ & 0.574 \\
\hline CDBP, mm Hg & $78.37 \pm 11.68$ & $74.16 \pm 11.00$ & 0.145 & $79.16 \pm 12.95$ & $75.61 \pm 12.68$ & 0.150 \\
\hline Aix@75, \% & $20.63 \pm 12.93$ & $13.53 \pm 11.66$ & 0.023 & $25.35 \pm 12.42$ & $20.79 \pm 9.85$ & 0.033 \\
\hline CAD, n (\%) & 15 (78.9) & $36(48.0)$ & 0.016 & $39(79.6)$ & $50(80.6)$ & 0.890 \\
\hline GS & $33.26 \pm 27.75$ & $21.16 \pm 27.90$ & 0.094 & $43.11 \pm 33.78$ & $32.16 \pm 33.20$ & 0.090 \\
\hline $\log _{2} \mathrm{GS}$ & $4.05 \pm 2.09$ & $2.67 \pm 2.54$ & 0.031 & $4.72 \pm 1.74$ & $3.91 \pm 2.16$ & 0.035 \\
\hline
\end{tabular}

CSBP = Central aortic systolic blood pressure; CBBP = Central aortic diastolic blood pressure. 
Table 4. Relative risk between arterial stiffness and CAD

\begin{tabular}{|c|c|c|c|}
\hline & CAD, n (\%) & OR $(95 \%$ CI $)$ & $\mathrm{p}$ value \\
\hline \multicolumn{4}{|l|}{$P W V$} \\
\hline \multicolumn{4}{|l|}{ Total population } \\
\hline$<10$ m/s $(\mathrm{n}=66)$ & $36(54.5)$ & 1.00 & NA \\
\hline $11-12 \mathrm{~m} / \mathrm{s}(\mathrm{n}=74)$ & $49(66.2)$ & $1.633(0.825-3.234)$ & 0.160 \\
\hline$>12$ m/s (n = 65) & 55 (84.6) & $4.583(1.999-10.510)$ & $<0.001$ \\
\hline \multicolumn{4}{|l|}{ CKD patients } \\
\hline$<11$ m/s $(\mathrm{n}=22)$ & $14(63.6)$ & 1.00 & NA \\
\hline $12-13 \mathrm{~m} / \mathrm{s}(\mathrm{n}=23)$ & $19(82.6)$ & $2.714(0.680-10.839)$ & 0.157 \\
\hline$>13 \mathrm{~m} / \mathrm{s}(\mathrm{n}=23)$ & 21 (91.3) & $6.000(1.106-32.537)$ & 0.026 \\
\hline \multicolumn{4}{|l|}{ Aix@75 } \\
\hline \multicolumn{4}{|l|}{ Total population } \\
\hline$<15(\mathrm{n}=70)$ & $44(62.9)$ & 1.00 & NA \\
\hline $15-24(\mathrm{n}=66)$ & $41(62.1)$ & $0.969(0.484-1.941)$ & 0.930 \\
\hline$>24(\mathrm{n}=69)$ & 55 (79.7) & $2.321(1.084-4.969)$ & 0.028 \\
\hline \multicolumn{4}{|l|}{ CKD patients } \\
\hline$<18(\mathrm{n}=23)$ & $15(65.2)$ & 1.00 & NA \\
\hline $18-30(\mathrm{n}=23)$ & $19(82.6)$ & $2.533(0.639-10.049)$ & 0.187 \\
\hline$>30(\mathrm{n}=23)$ & $20(90.9)$ & $5.333(0.986-28.844)$ & 0.039 \\
\hline
\end{tabular}

in the lowest PWV and Aix@75 group, patients with the highest PWV and Aix@75 values suffered significantly more often from CAD.

To further view the independent risk factors for increased arterial stiffness, logistic regression analysis was conducted for factors which had a $\mathrm{p}$ value $<0.2$ in univariate analysis (table 5), and the results revealed CKD to be an independent risk factor (OR $=2.508,95 \% \mathrm{CI}$ $1.308-4.808, p=0.006$ ) for increased arterial stiffness. However, hypertension was not found to be significant (OR $=1.524,95 \%$ CI $0.795-2.922, \mathrm{p}=0.204$ ) in this study, which may be due to the high prevalence of hypertension $(74.2 \%)$ in the total population and the masking effect of the other risk factors.

\section{Long-Term Outcomes and Arterial Stiffness in the Whole and CKD Population}

We achieved a 5 -year follow-up rate of $93.66 \%$ in a total of 192 patients, with a $100 \%$ $(\mathrm{n}=116)$ follow-up rate in patients receiving percutaneous coronary intervention (PCI). For the whole population, Kaplan-Meier curves showed no significant MACE-free rate difference between CKD and non-CKD patients (fig. 1a), but CKD patients had a higher MACE rate if they had received PCI compared with non-CKD patients (fig. 1b). We further analyzed CKD patients who had received PCI at baseline and found that the MACE rate was significantly higher in those who had a PWV >13 m/s or Aix@ $75>30$ (fig. 1c, d). Thus, this indicates that CKD patients with increased arterial stiffness have a poorer prognosis.

\section{Discussion}

Only in this decade has CKD been recognized to be a great risk factor for CAD $[1,3,7$, 11-14]. Recently, The Lancet published a population-level cohort study, which enrolled 1.3 million participants and suggested that CKD could be added to the list of criteria defining people at highest risk of future coronary events [15]. After this, the 2013 ESC guidelines on stable CAD [16] have declared CKD as being a risk factor for, and to be strongly associated 
Table 5. Univariate and multivariate analysis of risk factors for increased and normal arterial stiffness a Univariate analysis

\begin{tabular}{|c|c|c|c|}
\hline & $\begin{array}{l}\text { Increased arterial } \\
\text { stiffness }(n=103)\end{array}$ & $\begin{array}{l}\text { Normal arterial } \\
\text { stiffness }(n=102)\end{array}$ & $\mathrm{p}$ value \\
\hline Age $>60$ years & $76(73.8)$ & $35(34.3)$ & $<0.001$ \\
\hline Female gender & $29(28.2)$ & $22(21.6)$ & 0.275 \\
\hline CAD & $80(77.7)$ & $60(58.8)$ & 0.004 \\
\hline Current smoker & $24(23.3)$ & $34(33.3)$ & 0.111 \\
\hline Hypertension & $81(78.6)$ & $71(69.6)$ & 0.140 \\
\hline Diabetes & $31(30.1)$ & $17(16.7)$ & 0.023 \\
\hline Dyslipidmia & $57(55.3)$ & $29(28.4)$ & $<0.001$ \\
\hline CKD & $47(45.6)$ & $21(20.6)$ & $<0.001$ \\
\hline \multicolumn{4}{|l|}{ Drug therapy } \\
\hline Aspirin & $95(92.2)$ & $90(88.2)$ & 0.335 \\
\hline ACEI & $65(63.1)$ & $53(52.0)$ & 0.106 \\
\hline Angiotensin receptor blocker & $28(27.2)$ & $35(34.4)$ & 0.269 \\
\hline Calcium channel blockers & $36(35.0)$ & $32(31.4)$ & 0.586 \\
\hline$\beta$-Blocker & $72(69.9)$ & $74(72.5)$ & 0.676 \\
\hline Statins & $90(87.4)$ & $88(86.3)$ & 0815 \\
\hline Nitrates & $44(42.7)$ & $50(49.0)$ & 0.365 \\
\hline \multicolumn{4}{|l|}{ Values are presented as $\mathrm{n}(\%)$} \\
\hline \multicolumn{4}{|l|}{ b Multivariate analysis } \\
\hline & OR & $95 \% \mathrm{CI}$ & $\mathrm{p}$ value \\
\hline Age $>60$ years & 5.010 & $2.645-9.490$ & $<0.001$ \\
\hline CKD & 2.508 & $1.308-4.808$ & 0.006 \\
\hline Dyslipidemia & 2.375 & $1.287-4.382$ & 0.006 \\
\hline Diabetes mellitus & 1.929 & $0.957-3.888$ & 0.066 \\
\hline
\end{tabular}

with, CAD, which has a major impact on outcomes and therapeutic decisions. In the current study, we found a close relationship between CKD, arterial stiffness and CAD, and we also revealed the influence of CKD and arterial stiffness on 5-year outcomes.

Arterial stiffness occurs stepwise with increasing stages of CKD [17]. As Seifert et al. [18] have recently reported, patients with stage 3 CKD exhibited increasing left ventricular mass, persistent left ventricular diastolic dysfunction and vascular stiffness, which is consistent with our data. Previous studies have pointed out that Aix and PWV were risk factors for CAD $[19,20]$, while our results also showed a higher occurrence of CAD in patients with high Aix and PWV indexes. These results indicated that, in CKD patients, the progression of coronary artery lesions could be accelerated by increased arterial stiffness. Moreover, an increased ED and decreased subendocardial viability ratio representing poorer diastolic function were other causes of coronary artery hypoperfusion.

Duprez and Cohn [21] reported that arterial stiffness was a valuable marker in predicting cardiovascular prognosis both cross-sectional and longitudinal. Levisianou et al. [22] also reported a higher reoccurrence rate of acute coronary events in diabetic patients with increased arterial stiffness. In the current study, we found a worse prognosis in CKD patients after coronary artery revascularization, which is consistent with our previous report [1]. Interestingly, CKD patients with an increased arterial stiffness index (PWV or Aix) had even 


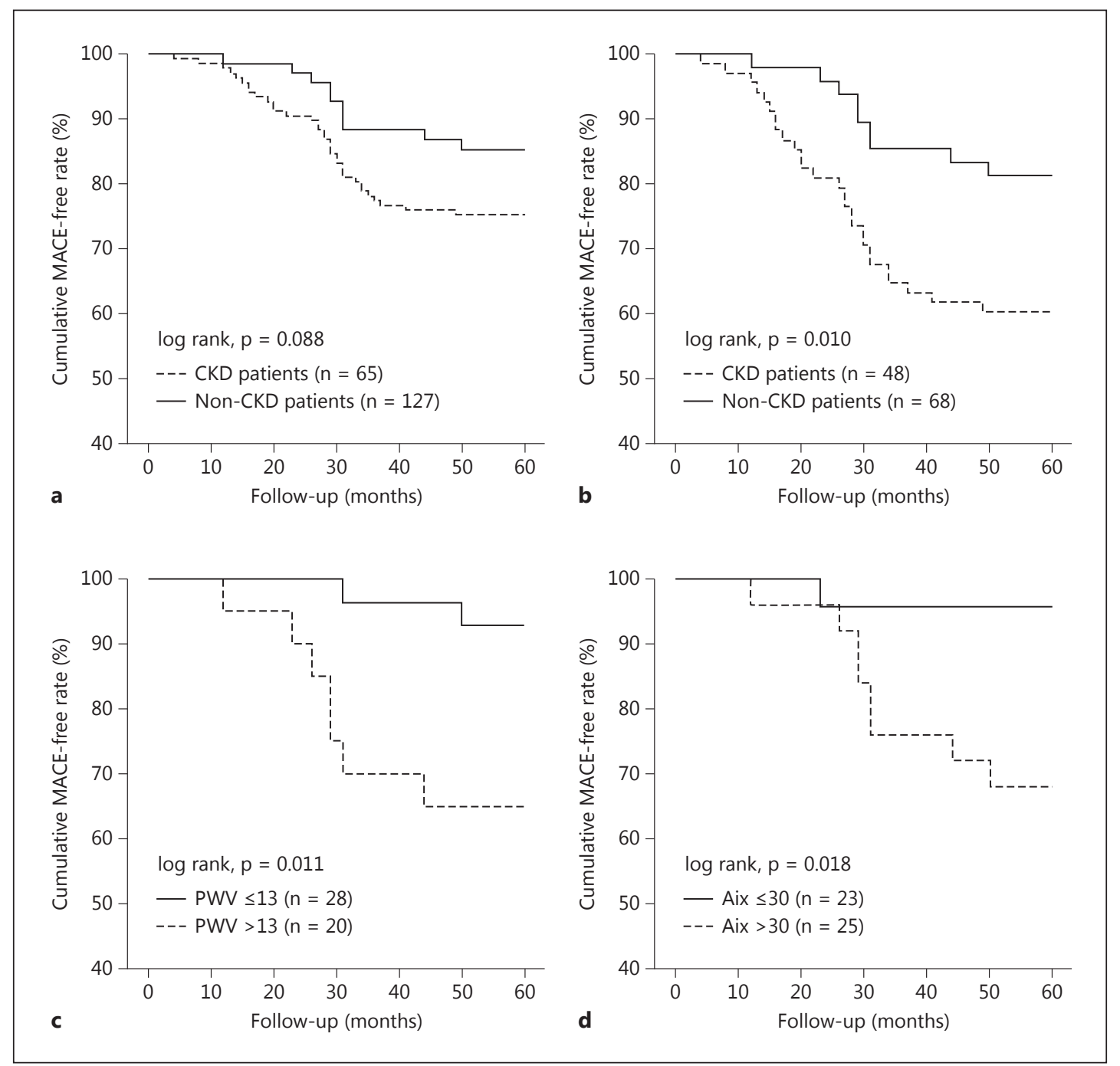

Fig. 1. MACE-free rates between CKD and non-CKD patients in the whole population (a) and in patients who received PCI (b). CKD patients who received PCI were further analyzed according to different PWV (c) and Aix levels (d).

worse long-term outcomes in the 5-year survival analysis. This evidence highlights the correlation between arterial stiffness, CKD and cardiovascular disease and suggests further clinical use of the arterial stiffness index.

Although many risk factors for CKD have long been known, arguments about risk equivalents for CAD in high-risk patients are unlikely to vanish in the near future. Researchers have reached a consensus that the lack of approved surrogate endpoints for kidney disease progression makes testing therapies to slow progression very challenging and expensive in improving cardiovascular outcomes [23,24]. Weir and Townsend [25] share this opinion and found out vascular stiffness could be used as a surrogate measure of mortality in CKD patients. Further studies should help to figure out whether treating strategies that target arterial stiffness or intensive treatments such as lipid lowering in CKD patients with increased arterial stiffness are valuable for improving CAD outcomes. 
The current study is a single-center study and is not projected as a paired design; thus, biases such as age and diabetes were not avoidable, and only limited epidemiological information for East China can be provided. Coronary artery calcification, which is more common in CKD patients [26] and is correlated with CAD prognosis especially after PCI, was not assessed in this study. Apart from these limitations, arterial stiffness index data were also not acquired by the end of follow-up.

\section{Acknowledgements}

This study was sponsored by the Eleventh (2006BAI01A03) and Twelfth (National Key Technology R\&D Program 2011BAI10B06) National Five-Year Science and Technology Support Plan.

\section{Disclosure Statement}

The authors have no conflicts of interest to declare.

\section{References}

1 Zhang RY, Zhu ZB, Zhang Q, Yang ZK, Hu J, Lv AK, Zhang JS, Shen WF: Impact of moderate or severe renal insufficiency on long-term outcomes in patients undergoing drug-eluting stent based coronary intervention. Int J Cardiol 2009;136:72-79.

-2 Bao YS, Na SP, Jia XB, Liu RC, Wang MA, Yu CY, Mu SH, Xie RJ: Prevalence and risk factors for chronic kidney disease in patients with coronary artery disease. Curr Med Res Opin 2012;28:379-384.

-3 Afsar B, Turkmen K, Covic A, Kanbay M: An update on coronary artery disease and chronic kidney disease. Int J Nephrol 2014;2014:767424.

-4 Briasoulis A, Bakris GL: Chronic kidney disease as a coronary artery disease risk equivalent. Curr Cardiol Rep 2013;15:340.

5 Jia G, Aroor AR, Sowers JR: Arterial stiffness: a nexus between cardiac and renal disease. Cardiorenal Med 2014;4:60-71.

-6 Bellasi A, Ferramosca E, Ratti C: Arterial stiffness in chronic kidney disease: the usefulness of a marker of vascular damage. Int J Nephrol 2011;2011:734832.

7 Roos CJ, Delgado V, de Koning EJ, Rabelink TJ, Jukema JW, Bax JJ, Scholte AJ: Associations of atherosclerosis in the descending thoracic aorta on CTA with arterial stiffness and chronic kidney disease in asymptomatic patients with diabetes mellitus. Int J Cardiovasc Imaging 2014;30:1151-1159.

-8 Inker LA, Astor BC, Fox CH, Isakova T, Lash JP, Peralta CA, Kurella Tamura M, Feldman HI: KDOQI US commentary on the 2012 KDIGO clinical practice guideline for the evaluation and management of CKD. Am J Kidney Dis 2014;63:713-735.

-9 Gensini GG: A more meaningful scoring system for determining the severity of coronary heart disease. Am J Cardiol 1983;51:606.

10 Mancia G, De Backer G, Dominiczak A, Cifkova R, Fagard R, Germano G, Grassi G, Heagerty AM, Kjeldsen SE, Laurent S, Narkiewicz K, Ruilope L, Rynkiewicz A, Schmieder RE, Boudier HA, Zanchetti A: 2007 ESH-ESC practice guidelines for the management of arterial hypertension: ESH-ESC Task Force on the management of arterial hypertension. J Hypertens 2007;25:1751-1762.

11 Covic A, Kothawala P, Bernal M, Robbins S, Chalian A, Goldsmith D: Systematic review of the evidence underlying the association between mineral metabolism disturbances and risk of all-cause mortality, cardiovascular mortality and cardiovascular events in chronic kidney disease. Nephrol Dial Transplant 2009;24:1506-1523.

12 Shroff GR, Frederick PD, Herzog CA: Renal failure and acute myocardial infarction: clinical characteristics in patients with advanced chronic kidney disease, on dialysis, and without chronic kidney disease. A collaborative project of the United States Renal Data System/National Institutes of Health and the National Registry of Myocardial Infarction. Am Heart J 2012;163:399-406.

-13 Ferdinand KC, Rodriguez F, Nasser SA, Caballero AE, Puckrein GA, Zangeneh F, Mansour M, Foody JM, Pemu PE, Ofili EO: Cardiorenal metabolic syndrome and cardiometabolic risks in minority populations. Cardiorenal Med 2014;4:1-11.

14 Eren Z, Ozveren O, Buvukoner E, Kaspar E, Degertekin M, Kantarci G: A single-centre study of acute cardiorenal syndrome: incidence, risk factors and consequences. Cardiorenal Med 2012;2:168-176. 


\section{CardioRenal Medicine}

\begin{tabular}{l|l}
\hline \multicolumn{2}{l}{ Cardiorenal Med 2014;4:280-289 } \\
\hline DOI: 10.1159/000369107 & $\begin{array}{l}\text { ( 2)14 S. Karger AG, Basel } \\
\text { www.karger.com/crm }\end{array}$ \\
\hline
\end{tabular}

Zhu et al.: Arterial Stiffness Correlates with CAD Outcomes in CKD Patients

15 Tonelli M, Muntner P, Lloyd A, Manns BJ, Klarenbach S, Pannu N, James MT, Hemmelgarn BR: Risk of coronary events in people with chronic kidney disease compared with those with diabetes: a population-level cohort study. Lancet 2012;380:807-814.

16 Montalescot G, Sechtem U, Achenbach S, et al: 2013 ESC Guidelines on the management of stable coronary artery disease: the Task Force on the management of stable coronary artery disease of the European Society of Cardiology. Eur Heart J 2013;34:2949-3003.

17 Wang MC, Tsai WC, Chen JY, Huang JJ: Stepwise increase in arterial stiffness corresponding with the stages of chronic kidney disease. Am J Kidney Dis 2005;45:494-501.

18 Seifert ME, de Las Fuentes L, Ginsberg C, Rothstein M, Dietzen DJ, Cheng SC, Ross W, Windus D, Davila-Roman VG, Hruska KA: Left ventricular mass progression despite stable blood pressure and kidney function in stage 3 chronic kidney disease. Am J Nephrol 2014;39:392-399.

19 Weber T, Auer J, O’Rourke MF, Kvas E, Lassnig E, Berent R, Eber B: Arterial stiffness, wave reflections, and the risk of coronary artery disease. Circulation 2004;109:184-189.

20 Guerin AP, Blacher J, Pannier B, Marchais SJ, Safar ME, London GM: Impact of aortic stiffness attenuation on survival of patients in end-stage renal failure. Circulation 2001;103:987-992.

21 Duprez DA, Cohn JN: Arterial stiffness as a risk factor for coronary atherosclerosis. Curr Atheroscler Rep 2007; 9:139-144.

-22 Levisianou D, Foussas S, Skopelitis E, Adamopoulou E, Xenopoulou T, Destounis A, Koukoulis G, Skoularigis I, Melidonis A, Triposkiadis F: Arterial stiffness predicts risk for long-term recurrence in patients with type 2 diabetes admitted for acute coronary event. Diabetes Res Clin Practice 2013;99:315-320.

23 Rubin MF, Rosas SE, Chirinos JA, Townsend RR: Surrogate markers of cardiovascular disease in CKD: what's under the hood? Am J Kidney Dis 2011;57:488-497.

24 Decker E, Kendrick J: Research in the CKD clinic: highs and lows. Adv Chronic Kidney Dis 2014;21:344-348.

-25 Weir MR, Townsend RR: Vascular stiffness as a surrogate measure of mortality in patients with chronic kidney disease. J Hypertens 2014;32:744-745.

26 Stompór T: Coronary artery calcification in chronic kidney disease: an update. World J Cardiol 2014;6:115129. 